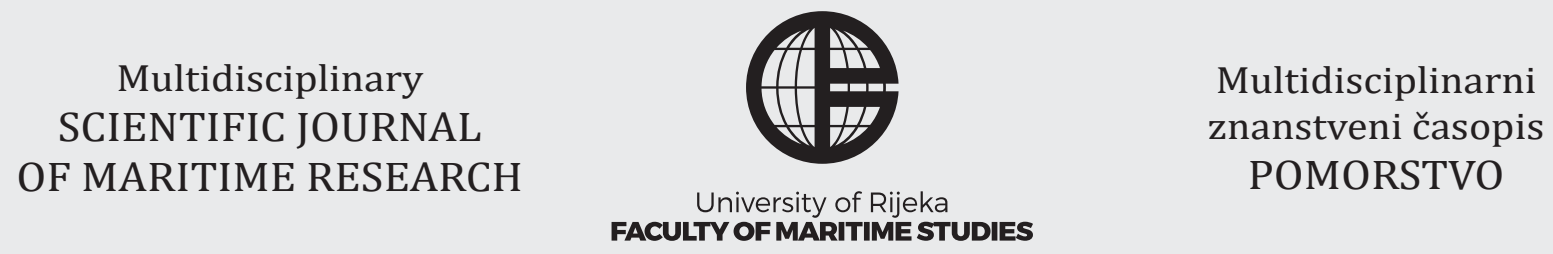

\title{
Fuzzy Cost Modelling of Diving Chamber Control Measures under Uncertainties
}

\author{
Thaddeus Chidiebere Nwaoha ${ }^{1}$, Ikuobase Emovon ${ }^{2}$ \\ ${ }^{1}$ Marine Engineering Department, Federal University of Petroleum Resources, Effurun, PMB 1221, Delta State, Nigeria, \\ e-mail: nwaoha.thaddeus@fupre.edu.ng \\ ${ }^{2}$ Mechanical Engineering Department, Federal University of Petroleum Resources, Effurun, PMB 1221, Delta State, Nigeria, \\ e-mail: emovon.ikuobase@fupre.edu.ng
}

\section{ABSTRACT}

The diving chamber is an important system needed for diving operations in the oil and gas industry. Divers use it for various purposes. Thus, the safety level of the diving chamber needs to be very high at all times and the system needs to be in a good state. To achieve this, various control measures such as control measures 1 and 2 can be adopted in preventing failures/hazards or mitigate their consequences. In this study, fuzzy cost algorithm is used to estimate the cost of using control measures 1 and 2 in ensuring optimal operational level for the diving chamber, while the preference degree approach is adopted in prioritizing the aforementioned cost of control measures 1 and 2. The result of the analysis indicated that control measure 2 is the most cost effective approach.

\section{ARTICLE INFO}

Review article

Received 21 October 2019

Accepted 1 October 2020

\author{
Key words: \\ Saturation chamber \\ Cost, fuzzy \\ Safety \\ Divers \\ Oil and gas
}

\section{Introduction}

A diving chamber is utilized in diving operations. It is made up of mechanical, electrical/electronics, structural systems, and subsystems. The diving chamber serves as a simpler form of submersible vessel that can be used to transport divers underwater, thus providing a temporary base for the diver and serves as a retrieval system too [1]. It is also used to create artificial undersea conditions for divers to experience. In such situations, pressures above normal atmospheric pressure are experienced by the divers. The diving chamber is utilised in carrying high pressure storage cylinders, communications, and emergency equipment for divers. It is utilised as an underwater base for surface supplied diving operations, giving room for the divers' umbilical (air supply, etc.) to be attached to it.

Currently, two types of diving chambers such as open diving chamber and hyperbaric chamber are used in the industries [2]. The open diving chamber is unique because it has an open bottom that automatically equalises internal air pressure and external water pressure with great simplicity and can be used in the underwater environment because of its characteristic such as internal air pressure directly proportional to the underwater depth. A hyperbaric chamber is a sealable pressure vessel with hatches that can accommodate divers, compressed breathing gas, thus providing oxygen to the divers [2]. It can be used in underwater, at the water surface and, on land to produce underwater pressures. A hyperbaric chamber can be called a decompression or recompression chamber $[3,4]$.

A decompression chamber is utilized by divers to make their surface decompression stops, while the recompression chamber, is employed for treatment or prevention of decompression sickness [3, 4]. According to Zamboni et. al. (1990) [1], a hyperbaric chamber is specifically used to take divers that are brought up from underwater through their decompression stops and treat decompression sickness; to train divers on adaptation in hyperbaric conditions, and performance assessment under pressure; to treat people using raised oxygen pressure in hyperbaric oxygen therapy; to treat people infected with gas gangrene and other conditions unrelated to diving; and for scientific research in elevated gas pressures. The safety of 
the diving chamber is paramount for effective diving operations. In view of this, the paper is structured as Section 2: Description of Safety of Diving Chamber; Section 3: Fuzzy Cost Algorithm; Section 4: Prioritization of Fuzzy Cost Estimates of Control Measures Conclusion; Section 5: Demonstration of Workability of Fuzzy Cost Algorithm in Divng Chamber Control Measure Cost Modelling and Section 6: Conclusions.

\section{Description of Safety of Diving Chamber}

Safe operation and maintenance of a diving chamber are vital in the various offshore activities, they are engaged in. To avoid accidents/hazards/failures when using the diving chamber, various hazards/failures need to be identified. In view of this, hazards/failures associated with the diving chamber are outlined as fire and explosion, flooding, oxygen poisoning, chamber structural integrity failure, communication failure and power supply failure using a brainstorming method. Brainstorming is a technique for tapping the creative thinking of a team to generate and clarify a list of ideas, problems, and issues [5]. Fire and explosion occur in a diving chamber when spark source is been experienced in the presence of oxygen content of the chamber. Fire burns in the presence of oxygen, fuel, and heat. The fuel can be the diver inside and the heat can be any source of metal with such capability to ignite the spark. Consequences can be revealed using event tree analysis as evidenced in [6, 7, 8, 9]. Flooding can occur when the chamber's hatch is opened. This can be disastrous as water flooding in will damage the equipment, waste the pure oxygen inside, and can be harmful to the diver who is just adapting to the underwater pressure. Oxygen poisoning is experienced when too much of the pure oxygen in the elevated pressure environment of the chamber is inhaled by the inexperienced diver, thus resulting in severe health damages.

Chamber structural integrity failure is experienced as a result of wrong material selection during the design stage of the system. Once the steel composition of the chamber is subjected to high internal pressure, the steel fails, which can be catastrophic to the system or diver. Communication failure is experienced when the walkie talkie use by experts passing information to the diver malfunctions. It can be as a result of frequency jamming. This can lead to misinformation of the true state of the diver. The relevance of failure mode effect and criticality analysis can be utilized in further investigation of such hazard. Failure mode, effect and criticality analysis methodology can be found in various publications [5, 10,11, 12, 13].

Power supply failure can occur due to the malfunction of some of the electrical based appliances in the chamber. The shortage of electricity supply when the chamber is being used will automatically lead to the stop of the flow of oxygen into the chamber, which can result to exhale of carbon-dioxide by the diver. If air is not recirculated into the chamber, the diver loses oxygen in the chamber and soon suffocates. Detail causes of the power supply failure can be investigated using the FTA method. FTA is carried out using a deductive analysis from the top event, which is the undesired event followed by causal relationships of the failures leading to that event [14]. To address these hazards/failures, control mechanisms/measures need to be developed and the most cost effective one identified using the fuzzy cost algorithm. Notable researchers have utilized such algorithm in addressing cost estimation problems under certainties as evidenced in various publications [5, $15,16,17,18,19]$. The insight provided in their work will be adopted to address the subject under investigation.

\section{Fuzzy Cost Algorithm}

Fuzzy set theory is an algorithm and mathematical formalization that enables the representation of the degree of membership of members in sets [15]. It utilizes linguistic variables in solving cost estimation problems under uncertainties. Fuzzy cost estimation of control measures on an engineering system can be facilitated, using Tables 1 and 2. Suppose cost estimation for control measure is denoted as $C_{i}^{l}$ in terms of cost expressions using Table 1. Equation 1 can be used to demonstrate the membership functions of the $C_{i^{\prime}}^{l}$ Membership functions of $C_{i}^{l}$ can be estimated using Table 1.

$$
C_{i}^{l}=\left(\frac{\mu_{C_{i}^{1}}^{1}}{1}, \frac{\mu_{C_{i}^{1}}^{2}}{2}, \frac{\mu_{C_{i}^{1}}^{3}}{3}, \frac{\mu_{C_{i}^{1}}^{4}}{4}, \frac{\mu_{C_{i}^{1}}^{5}}{5}, \frac{\mu_{C_{i}^{1}}^{6}}{6}, \frac{\mu_{C_{i}^{1}}^{7}}{7}\right)
$$

To map the fuzzy cost description onto utility expression in Table 2, the best-fit method is utilized. The best fit method utilizes the distance between $C_{i}^{l}$ and each of the

Table 1 Cost Expression Linguistic Variables and Associated Fuzzy Memberships [5, 19].

\begin{tabular}{|c|c|}
\hline $\begin{array}{c}\text { Linguistic Variables } \\
\boldsymbol{\mu L}\end{array}$ & $\begin{array}{c}\text { Fuzzy Membership and } \\
\text { their Categories }\end{array}$ \\
\hline $\begin{array}{c}\text { Very high } \\
\left(\mu_{L}^{\text {Veryhigh }}\right)\end{array}$ & $\left(\frac{0}{1}, \frac{0}{2}, \frac{0}{3}, \frac{0}{4}, \frac{0}{5}, \frac{0.75}{6}, \frac{1}{7}\right)$ \\
\hline $\begin{array}{c}\text { High } \\
\left(\mu_{L}^{\text {High }}\right)\end{array}$ & $\left(\frac{0}{1}, \frac{0}{2}, \frac{0}{3}, \frac{0}{4}, \frac{0.75}{5}, \frac{1}{6}, \frac{0.25}{7}\right)$ \\
\hline $\begin{array}{c}\text { Moderately high } \\
\left(\mu_{L}^{\text {Moderatehigh }}\right)\end{array}$ & $\left(\frac{0}{1}, \frac{0}{2}, \frac{0}{3}, \frac{0.5}{4}, \frac{1}{5}, \frac{0.25}{6}, \frac{0}{7}\right)$ \\
\hline $\begin{array}{c}\text { Average } \\
\left(\mu_{L}^{\text {Average }}\right)\end{array}$ & $\left(\frac{0}{1}, \frac{0}{2}, \frac{0.5}{3}, \frac{1}{4}, \frac{0.5}{5}, \frac{0}{6}, \frac{0}{7}\right)$ \\
\hline $\begin{array}{c}\text { Moderately low } \\
\left(\mu_{L}^{\text {Moderatelow }}\right)\end{array}$ & $\left(\frac{0}{1}, \frac{0.25}{2}, \frac{1}{3}, \frac{0.5}{4}, \frac{0}{5}, \frac{0}{6}, \frac{0}{7}\right)$ \\
\hline $\begin{array}{l}\text { Low } \\
\left(\mu_{L}^{\text {Low }}\right)\end{array}$ & $\left(\frac{0.25}{1}, \frac{1}{2}, \frac{0.75}{3}, \frac{0}{4}, \frac{0}{5}, \frac{0}{6}, \frac{0}{7}\right)$ \\
\hline $\begin{array}{l}\text { Very low } \\
\left(\mu_{L}^{\text {Verylow }}\right)\end{array}$ & $\left(\frac{1}{1}, \frac{0.75}{2}, \frac{0}{3}, \frac{0}{4}, \frac{0}{5}, \frac{0}{6}, \frac{0}{7}\right)$ \\
\hline
\end{tabular}


Table 2 Utility Expression Linguistic Variables and Associated Fuzzy Memberships [5, 19].

\begin{tabular}{|c|c|}
\hline $\begin{array}{c}\text { Linguistic Variables } \\
\mu_{C}\end{array}$ & $\begin{array}{c}\text { Fuzzy Membership and } \\
\text { their Categories }\end{array}$ \\
\hline $\begin{array}{l}\text { Slightly preferred } \\
\left(\mu_{C}^{\text {Slightlypreferred })}\right.\end{array}$ & $\left(\frac{0}{1}, \frac{0}{2}, \frac{0}{3}, \frac{0}{4}, \frac{0}{5}, \frac{0.75}{6}, \frac{1}{7}\right)$ \\
\hline $\begin{array}{l}\text { Moderately preferred } \\
\left(\mu_{C}^{\text {Moderatepreferred })}\right.\end{array}$ & $\left(\frac{0}{1}, \frac{0}{2}, \frac{0}{3}, \frac{0.5}{4}, \frac{1}{5}, \frac{0.25}{6}, \frac{0}{7}\right)$ \\
\hline $\begin{array}{l}\text { Preferred } \\
\left(\mu_{C}^{\text {Preferred })}\right)\end{array}$ & $\left(\frac{0}{1}, \frac{0.25}{2}, \frac{1}{3}, \frac{0.5}{4}, \frac{0}{5}, \frac{0}{6}, \frac{0}{7}\right)$ \\
\hline $\begin{array}{l}\text { Greatly preferred } \\
\left(\mu_{C}^{\text {Greatlypreferred })}\right.\end{array}$ & $\left(\frac{1}{1}, \frac{0.75}{2}, \frac{0}{3}, \frac{0}{4}, \frac{0}{5}, \frac{0}{6}, \frac{0}{7}\right)$ \\
\hline
\end{tabular}

utility expressions in Table 2 . The distance represents the extent to which $C_{i}^{l}$ is confirmed to each of the defined utility expressions $[5,15,20,21]$. Equation 2 , can be used to obtain the aforementioned distance.

$d_{i 1}^{l}\left(C_{i}^{l}\right.$, slightly preferred $)=\left[\sum_{j=1}^{7}\left(\mu_{C_{i}^{l}}^{j}-\mu_{\text {slightly preferred }}^{j}\right)^{2}\right]^{1 / 2}$

$d_{i 2}^{l}\left(C_{i}^{l}\right.$, moderately preferred $)=\left[\sum_{j=1}^{7}\left(\mu_{c_{i}^{l}}^{j}-\mu_{\text {moderately preferred }}^{j}\right)^{2}\right]^{1 / 2}$

$d_{i 3}^{l}\left(C_{i}^{l}\right.$, preferred $)=\left[\sum_{j=1}^{7}\left(\mu_{c_{i}^{j}}^{j}-\mu_{\text {preferred }}^{j}\right)^{2}\right]^{1 / 2}$

$d_{i 4}^{l}\left(C_{i}^{l}\right.$, greatly preferred $)=\left[\sum_{j=1}^{7}\left(\mu_{C_{l}^{l}}^{j}-\mu_{\text {greatly preferred }}^{j}\right)^{2}\right]^{1 / 2}$

Each $d_{i j}^{l}=(j=1,2,3,4)=$ an unscaled distance. In situation, $d_{i j}^{l}=0$, values of membership functions of fuzzy cost description $C_{i}^{l}=$ the $j$ th utility expressions in Table $2 . \lambda_{i j}^{l}=(j$ $=1,2,3,4)$ are the inverse of $d_{i j}^{l}$ as illustrated in Equation 3.

$$
\lambda_{i j}^{l}=\frac{1}{d_{i j}^{l}}, j=1,2,3,4
$$

Each $\mu_{C_{i}^{l}}^{j}=(j=1,2,3,4)$ is the extent to which $C_{i}^{l}$ is confirmed to the $j$ th defined utility expression. It is also the normalisation of $\lambda_{i j}^{l}$ as shown in Equation 4.

$$
\mu_{C_{i}^{j}}^{j}=\frac{\lambda_{i j}^{l}}{\sum_{n=1}^{4} \lambda_{i n}^{l}} j=1,2,3,4
$$

$\sum_{n=1}^{4} \lambda_{i n}^{l}$ is the summation of $\lambda_{i j}^{l}=(j=1,2,3,4)$ and must be equal to one. Estimated cost expression for a control measure under uncertainties can be revealed by mapping the values of $\mu_{C^{l}}^{j}=(j=1,2,3,4)$ onto the utility spaces as evidenced in Equation 5.

$$
U\left(C_{i}^{l}\right)=\left\{\begin{array}{l}
\left(\mu_{c_{i}^{l}}^{1}, \text { "slightly preferred" }\right), \\
\left(\mu_{\mathrm{C}_{i}^{1}}^{2}, " \text { moderately preferred" }\right), \\
\left(\mu_{\mathrm{C}_{i}}^{3}, " \text { preferred" }\right),\left(\mu_{C_{i}^{l}}^{4}, " \text { greatly preferred" }\right)
\end{array}\right\}
$$

In Equation 5, the $\mu_{c_{i}^{\prime}}^{1} \mu_{c^{\prime}}^{2} \mu_{c_{i}^{\prime}}^{3}$ and $\mu_{c_{i}^{\prime}}^{4}$ are the degree of beliefs to which control measure are described as "slightly preferred", "moderately preferred", "preferred" and "greatly preferred" respectively.

\section{Prioritization of Fuzzy Cost Estimates of Control Measures}

Prioritization of control measures is important because it reveals which measure is cost effective over others. To achieve this, the belief degrees associated with the obtained utility description $U\left(C_{i}^{l}\right)$ are incorporated in Equation $6[15,16,17,18]$.

$$
\begin{gathered}
H_{i}=0.217 \times \mu_{i}^{1}+0.478 \times \mu_{i}^{2}+0.739 \times \mu_{i}^{3}+1 \times \mu_{i}^{4}+ \\
\left(\frac{0.217+0.478+0.739+1}{4}\right) \times\left(1-\left(\mu_{i}^{1}+\mu_{i}^{2}+\mu_{i}^{3}+\mu_{i}^{4}\right)\right)
\end{gathered}
$$

where, $H_{i}(i=1 \ldots n)$ is the preference degree value for fuzzy cost estimate for a control measure. A larger $H_{i}$ mean that the cost estimate for a control measure is cheaper than others and vice versa.

\section{Demonstration of Workability of Fuzzy Cost Algorithm in Diving Chamber Control Measure Cost Modelling}

The diving chamber contributes immensely in saving the life of a diver after offshore operations, thus the safety needs to be at an optimal level during operations. To achieve this, various control measures can be used in preventing failures/hazards or mitigate their consequences. To control common hazards/failures found in the available literature, as evidenced in Sub-section 2, various control measures such as the control measures 1 and 2 have been identified. The control measure 1 entails insulation of equipment for heat prevention, supply of natural oxygen to the diver and use of experts in opening of the hatch of the diving chamber and in design, construction and maintenance of diving chamber, while control measure 2 are insulation of equipment for heat prevention, supply of natural oxygen to the diver and use of experts in opening of the hatch of the diving chamber and in design, construction and maintenance of diving chamber, and regular inspection of diving chamber systems and sub-systems. Due to the growing level of uncertainties, cost data for control measures 1and 2 posed to be a challenge. To address this, the fuzzy cost algorithm explained in Section 3 is logically applied step by step. 
Using Table 1, linguistic terms for fuzzy cost estimates for control measure 1 and control measure 2 are moderately low and very low respectively. The associated fuzzy cost values are $C_{1}=\left\{\frac{0}{1}, \frac{0.25}{2}, \frac{1}{3}, \frac{0.5}{4}, \frac{0}{5}, \frac{0}{6}, \frac{0}{7}\right\}$ for control measure 1 , and $C_{2}=\left\{\frac{1}{1}, \frac{0.75}{2}, \frac{0}{3}, \frac{0}{4}, \frac{0}{5}, \frac{0}{6}, \frac{0}{7}\right\}$.

Utilizing the best-fit method, the aforementioned fuzzy values produced utility cost estimates of $U\left(C_{1}\right)=\{(0$, "slightly preferred"), (0, "moderately preferred"), (1, "preferred"), (0, "greatly preferred")\} for control measure 1 and $U\left(C_{2}\right)=\{(0$, "slightly preferred"), $(0$, "moderately preferred"), (0, "preferred"), (1, "greatly preferred")\}for control measure 2. From the above description, it means that stakeholders/owners of the saturation chamber $100 \%$ "preferred" cost of control measure 1, and 100\% "greatly preferred" cost of control measure 2 .

To verify the result above, preference degree values associated with control measure 1 and control measure 2 are investigated using Equation 6. The belief degree values associated with the utility cost estimates of the control measure 1 and control measure 2 are incorporated in Equation 6 as follows:

$H_{1}$ for control measure $1=$

$$
\begin{aligned}
= & 0.217 \times \mu_{1}^{1}+0.478 \times \mu_{1}^{2}+0.739 \times \mu_{1}^{3}+1 \times \mu_{1}^{4}+ \\
& +\left(\frac{0.217+0.478+0.739+1}{4}\right) \times\left(1-\left(\mu_{1}^{1}+\mu_{1}^{2}+\mu_{1}^{3}+\mu_{1}^{4}\right)\right) \\
= & 0.217 \times 0+0.478 \times 0+0.739 \times 1+1 \times 0+0.6085(1-(0+0 \\
= & 0.739
\end{aligned}
$$

$\mathrm{H}_{2}$ for control measure $2=$

$$
\begin{aligned}
= & 0.217 \times \mu_{2}^{1}+0.478 \times \mu_{2}^{2}+0.739 \times \mu_{2}^{3}+1 \times \mu_{2}^{4}+ \\
& +\left(\frac{0.217+0.478+0.739+1}{4}\right) \times\left(1-\left(\mu_{2}^{1}+\mu_{2}^{2}+\mu_{2}^{3}+\mu_{2}^{4}\right)\right) \\
= & 0.217 \times 0+0.478 \times 0+0.739 \times 1+1 \times 1+ \\
& +0.6085(1-(0+0+0+1)) \\
= & 1.739
\end{aligned}
$$

Applying the principle of preference degree that states any control measure associated with the large value is the one with a cheaper cost, thus the most cost effective option. In view of this, control measure 2 is cheaper than control measure 1 because it has a preference degree value of 1.739 , thus rank as 1 . Therefore, the utility cost description $U\left(C_{1}\right)=\{(0$, "slightly preferred"), $(0$, "moderately preferred"), (1, "preferred"), (0, "greatly preferred")\} for control measure 1 and $U\left(C_{1 \mathrm{~B}}^{1}\right)=\{(0$, "slightly preferred" $)$, (0, "moderately preferred"), (0, "preferred"), (1, "greatly preferred")\}for control measure 2 are acceptable because they are in line with the prioritization.

\section{Conclusions}

The safety of the saturation chamber has been described, and various ways of managing them revealed. The cost implications of the control measures 1 and 2 that can ensure optimal safety level of the saturation chamber under uncertainties are estimated using a fuzzy cost algorithm. In the study, control measure 2 is identified as the most cost effective measure as evidenced by the preference degree value of 1.739 as compare to that of control measure 1 having a preference degree value of 0.739 .

\section{References}

[1] Zamboni, W. A., Riseman, J. A., and Kucan, J. O. (1990) “Management of Fournier's Gangrene and the role of Hyperbaric Oxygen". Journal of Hyperbaric Medicine, Vol. 5, Issue 3, pp. 177-186.

[2] Kindwall, E. P., Goldmann, R. W., Thombs, P. A. (1988) "Use of the Monoplace vs. Multiplace Chamber in the Treatment of Diving Diseases", Journal of Hyperbaric Medicine, Undersea and Hyperbaric Medical Society, Vol. 3, Issue 1, pp. 5-10.

[3] Lettnin, H. K. J. (1999) "International Textbook of Mixed Gas Diving: Theory Technique Applcation”, Best Publishing, ISBN 0941332500.

[4] Bevan, J. (1999) "Diving Bells through the Centuries", South Pacific Underwater Medicine Society Journal, Vol. 29, pp. 4250.

[5] Wang, J. and Trbojevic, V. M. (2007) "Design for Safety of Marine and Offshore Systems", Institute of Marine Engineering, Science and Technology, London.

[6] Kang, D. and Jung, Y. H. (2018) "Comparative Study on the Construction of Support System Initiating Event Fault Trees for a Fire Probabilistic Safety Assessment", Nuclear Engineering and Design, Vol. 332, pp. 345-356.

[7] Raiyan, A. Das, S. and Islam, M. R. (2017) "Event Tree Analysis of Marine Accidents in Bangladesh", Procedia Engineering, Vol. 194, pp. 276-283.

[8] Piadeh, F. Ahmadi, M. and Behzadian, K. (2018) "Reliability Assessment for Hybrid Systems of Advanced Treatment Units of Industrial Wastewater Reuse using Combined Event Tree and Fuzzy Fault Tree Analyses", Journal of Cleaner Production, Vol. 201, pp. 958-973.

[9] Nwaoha, T. C. and Emovon, I. (2018) "Facilitating Improvement of Design for Safety and Operations of a Seaweed Harvester: A Hybrid Traditional Safety Method", International Journal of Integrated Engineering, Vol. 10, No. 8, pp. 185-194.

[10] Chanamool, N. and Naenna, T. (2016) "Fuzzy FMEA Application to Improve Decision-making Process in an Emergency Department", Applied Soft Computing, Vol. 43, pp. 441-453.

[11] Balaraju, J. Raj, M. G. and Murthy, C. S. (2019) "Fuzzy-FMEA Risk Evaluation Approach for LHD Machine-A Case Study", Journal of Sustainable Mining, Vol. 18, Issue 4, pp. 257-268.

[12] Mete, S. (2019) "Assessing Occupational Risks in Pipeline Construction using FMEA-Based AHP-MOORA Integrated Approach under Pythagorean Fuzzy Environment", Journal of Human and Ecological Risk Assessment: An International Journal, Vol. 25, Issue 7, pp. 1645-1660.

[13] Yang, Z. and Wang, J. (2015) "Use of Fuzzy Risk Assessment in FMEA of Offshore Engineering Systems", Ocean Engineering, Vol. 95, pp. 195-204. 
[14] Nwaoha, T. C. Yang, Z. Wang, J. and Bonsall, S. (2011a) "Application of Genetic Algorithm (GA) to Risk-based Maintenance Operations of Liquefied Natural Gas (LNG) Carrier Systems", Journal of Process Mechanical Engineering, Vol. 225, No. 1, pp. 40-52.

[15] Nwaoha, T. C. Yang, Z. Wang, J. and Bonsall, S. (2013) "Adoption of New Advanced Computational Techniques to Hazards Ranking in LNG Carrier Operations", Ocean Engineering, Vol. 72, No. 1, pp. 31-44.

[16] Nwaoha, T. C. (2014) "Inclusion of Hybrid Algorithm in Optimal Operations of LNG Transfer Arm under Uncertainty", Ships and Offshore Structures, Vol. 9, Issue 5, pp. 514-524.

[17] Nwaoha, T. C. Adumene, S. and Thankgod, B. E. (2017) "Modelling Prevention and Reduction Methods of Ship Propeller Cavitation under Uncertainty", Ships and Offshore Structures, Vol. 12, Issue 4, pp. 452-460.
[18] Wang, J. Yang, J. B. and Sen, P. (1996) "Multi-person and Multi-attribute Design Evaluations Evidential Reasoning Based on Subjective Safety and Cost Analyses", Reliability Engineering and System Safety, Vol. 52, No. 2, pp. 113-128.

[19] Nwaoha, T. C. and John, A. (2016) "Some Insights in Novel Risk Modelling of the LNG Carrier Maintenance Operations" Journal of Marine Science and Application, Vol. 15, Issue 2, pp. 144-156.

[20] Nwaoha, T. C. Yang, Z. Wang, J. and Bonsall, S. (2011b) "A New Fuzzy Evidential Reasoning Method for Risk Analysis and Control of Liquefied Natural Gas (LNG) Carrier Containment System", Journal of Engineering for Maritime Environment, Vol. 225, No. 1, pp. 206-225.

[21] Wang, J. Yang, J. B. and Sen, P. (1995) "Safety Analysis and Synthesis Using Fuzzy Set Modelling and Evidential Reasoning", Reliability Engineering and System Safety, Vol. 47, pp. 103-118. 